THE RISE AND FALL OF NETVILLE:

\title{
THE SAGA OF A CYBERSPACE CONSTRUCTION BOOMTOWN \\ IN THE GREAT DIVIDE
}

\author{
John Leslie King \\ Rebecca E. Grinter ${ }^{\dagger}$ \\ Jeanne M. Pickering
}

Center for Research on Information Technology

and Organizations (CRITO)

University of California, Irvine

Irvine CA 92717

\footnotetext{
$\dagger^{\top}$ Rebecca E. Grinter is supported by a grant from the Engineering and Physical Sciences Research Council of the United Kingdom.
} 


\section{INTRODUCTION}

The challenge of merging technical and social skill bases for the purposes of building effective information technologies has been characterized as the problem of bridging a great divide between technical and social expertise (Star, 1993). But truly new technologies often emerge when technologists and their patrons create a great divide that shelters technical innovation from the status quo. ${ }^{1}$ Invention best arises within a narrow social context, not across all the social contexts it ultimately affects. Perhaps it could not otherwise survive. Yet when ultimately the technology is offered to the broader social world, the divide must be straddled, exposing the community that gave birth to the technology to normal powerful social forces that can destroy it.

This paper tells the story of the homesteading of the unique virtual settlement of Netville ${ }^{2}$ within which the Internet was born. The pioneers of Netville faced the hardships of a technological frontier but they also exploited a great divide - a zone of freedom and opportunity that allowed them to create something truly new. Netville was a community where deeply ingrained institutional values of intellectual curiosity, informal meritocratic reward structures, and egalitarian presumptions enabled a highly disaggregated and distributed population to work together to create an amazing artifact quite unlike any seen before. Through their labors, the people of Netville created cyberspace ${ }^{3}$ and a community that was geographically distributed but bound together by a shared interest in a technology that was both the subject and object of their efforts.

As glorious as the rise of Netville has proven to be in retrospect, it was largely unnoticed by the world at large during that rise. From the late 1960's through 1990, the

\footnotetext{
${ }^{1}$ The principle of institutionalized order, a key feature of this discussion, can be explored in detail in Meyer and Rowan (1977), DiMaggio and Powell (1983, 1991), March and Olsen (1992), and Scott (1992). A detailed discussion of this is provided in King, et. al, (1994).

${ }^{2}$ Netville is a name we have given the community of developers who worked together to provide the technologies which most people using the network today use.

${ }^{3}$ William Gibson first coined this term in his book Neuromancer (Gibson, 1984). Faced with trying to describe this space where people meet and talk electronically, a place constructed entirely of electric pulses which does not have any physical existence, he invented the term cyberspace. The book, a science fiction novel, caught the imagination of Netville. Neal Stephenson (1992) in his book Snow Crash has used the term metaverse to describe the same phenomenon.
} 
population of Netville grew slowly but steadily in an organic fashion. It drew to itself members of the research and high-technology communities who were willing to learn both the technical procedures and social conventions required for access to and residence in cyberspace. New members of the community found powerful incentives to conform to the social conventions of the earlier settlers, and to a great degree, Netville was a self-governing society with relatively few rules and relatively few rule breakers. This idyllic state began to change around 1990 as the news of Netville and of cyberspace began to spread to new domains - to commercial firms, non-profit organizations, and most importantly, the media. Soon the tides of immigration flooded Netville with new settlers, and with them came powerful new institutional interests that displaced the institutional forces that gave life to Netville. Within a few years, Netville had begun to change and the fall of Netville was underway. Cyberspace would survive, after many paleonymic grafts to reshape its meaning and image to fit the interests of the new institutional forces of commerce and entertainment. Netville, however, was destined for one of two futures: to die the death of many a construction boomtown, leaving empty buildings and the skeletal remains of life; or to be reborn as an entertainment spectacle like Las Vegas, and run by those who appreciate the drawing power of money and flesh. The rise and fall of Netville is a modern morality tale of vision, courage, and skill, and the nearly inevitable subordination of ideals to material progress. Cyberspace would suvive, after many paleonymic grafts to reshape its meaning and image to fit the interests of the new institutional forces of commerce and entertainment.

Netville emerges from the analysis that follows as a remarkable vital but fragile entity, capable of producing something that would change the world but unable to protect itself from the consequences of its own success. The story, ultimately, involves the clash of institutional interests and values in which the details of technology are critical for marking the progress of Netville and shaping its effect on the world, but play a remarkably subordinate role in the rise and fall of Netville as a community. In this story, Netville's future remains uncertain. It might die the death of many a construction boomtown, leaving empty buildings and the skeletal remains of life. It could as easily be reborn as an entertainment spectacle like Las Vegas, run by those who appreciate the drawing power of money and flesh. The rise and fall of Netville is a modern morality tale of vision, courage, skill, and the nearly inevitable subordination of ideals to material progress.

\section{THE RISE OF NETVILLE}


The question of when Netville began is difficult to answer, in part because the history is cloudy, and in part because the definitions of the key terms have evolved over time. ${ }^{4}$ As a practical matter, we focus our attention on the Netville era that produced three clear triumphs: demonstration of a robust internetworked system for packet switched communication (the ARPANET), which evolved into the Internet; electronic mail on that network, which allowed asynchronous text communications between all users of the network; and the hypertext-based World Wide Web, which evolved late in the life of Netville, bringing great new capabilities to the network. Nevertheless, we think it is worthwhile to fix a starting time for Netville. To do so we must at least determine when computer networking and electronic mail first emerged. We provide some historical context to make that challenge a bit easier to understand, and to facilitate our discussion of how Netville as a social community came to be.

\section{Technical Milestones}

Perhaps the first technical milestone of Netville was set around 1884 when the U.S. Congress paid Samuel Morse $\$ 30,000$ to build a telegraph link between Washington, D.C. and Baltimore (Thompson, 1947). Telegraphy cannot in any sense be seen as a computer network, but it was the first form of electronic mail, and it operated in a network fashion, with human operators at the nodes. The teletype ushered in a more recognizable form of electronic mail in 1931, providing text output readable directly by someone other than a telegraph operator (Beniger, 1986). The first remote use of a computer in 1940, using a Bell Laboratories Complex Number Calculator located in New York from a teletype in Hanover, New Hampshire, provides another marker of the beginning of Netville (Williams, 1985). However, none of these systems constituted what we would recognize today as a computer network.

The first true, real-time computer network was the Semi-Automatic Ground Environment (SAGE) air defense system developed in the early 1960's. SAGE was a sensing and process control system that ran over approximately one million miles of dedicated communication lines, linking several thousand graphics terminals driven by IBM/MIT AN/FSQ7 computers to AN/FSQ8 weapon control computers (Moreau, 1984). The facsimile machine could be considered a key marker in the electronic mail

\footnotetext{
${ }^{4}$ We thank David Crocker, Einar Stefferud and John Vittal for their personal insights that provided background and guidance for this discussion.
} 
world, given that it operated on a robust network that (at least now) is computer-based, and it transmitted text electronically. The birth of Netville could rightly be tied to any of these events. But none of them contains the key elements of today's Internet: a world in which non-computer experts communicate with one another through a computermediated communications network.

The Internet began with the sharing of messages between users on single-computer, online timesharing systems. While prosaic by today's standards, these machines represented important conceptual breakthroughs in both computing and communications technology (Moreau, 1984). The first commercial timeshared machine, the IBM 305, allowed up to four users to access shared applications and records almost simultaneously. A much more important breakthrough occurred in the development of the American Airlines/IBM joint project to develop an airline reservations system, SABRE, that allowed simultaneous access by more than 1,000 terminals. Unlike SAGE, which was really a system of sensors and actuators for process control to support the work of specialists, SABRE was an information system that allowed thousands of users with no previous experience with computers to communicate with a shared information resource. However, SABRE did not allow person-to-person communication through the timesharing system.

Email capability of the sort now common emerged in the evolution of sophisticated timesharing systems used in research environments. Remote users of these systems often needed to have the computer operator execute an operation such as a tape mount. Rather than telephone the operator, who was sitting at the computer operations console, it made more sense for the user to create a file that could be attached, via a command, to the operator's "inbox" mail file. It is possible that the first instance of this was the TENEX MAIL command, part of the TENEX operating system built by Bolt, Beranek and Newman Company for the Digital Equipment Corporation's PDP-10 computer in the late 1960s. The ARPANET mail feature grew directly out of this development when it was recognized that the TENEX MAIL command could be used with the recently created File Transfer Protocol feature (FTP), which allowed movement of files across network lines from machine to machine, to append mail files to the inboxes of users on remote machines. The TENEX MAIL command was added to FTP, setting the initial standard for ARPANET MAIL and eventually for the current Internet. It is difficult to say exactly when the first ARPANET message was sent, but it probably occurred around the time of the gala unveiling of the ARPANET at the Washington Hilton in 
1972 (Roberts and Kahn, 1972). However, reading mail was an unwieldy affair until the creation of RD (ReaDmail) in 1974. RD was a set of TECO macros to parse inboxes and preset the reader with messages as units of process, rather than just reading the raw file of appended inbox messages. This advance was rapidly followed by many new versions of ARPANET mail handlers that greatly facilitated email use and formed the basis of Netville's most significant practical achievement. From humble beginnings, electronic mail on the Internet has grown to huge proportions. Recently, the Nielsen research corporation estimated that more than 37 million people have ever used the Internet. Probably, electronic mail now supports the work of more than ten million people, with more joining as regular users each day.

If text-based electronic mail communications over packet switched computer communication networks marks the early period of Netville, the World Wide Web (WWW) represents the last great technical triumph of the community. ${ }^{5}$ The WWW began in 1989 at the European nuclear research center CERN as an in-house strategy to use computers to help coordinate projects. The essence of the WWW concept was the construction of a "browser" that allowed a user to move across the Internet looking into specially prepared files stored for the purpose of being browsed. The key idea was that the reader went looking for information rather than the user specifically distributing the information. The concept received the name World-Wide Web at CERN in 1990. In December of 1991, a poster session on the WWW was presented at the Hypertext conference, marking the first notification by this previously unrecognized group of hypertext developers in the established hypertext community. By late 1992, the WWW was in operation, hosted on computers at major energy laboratories and supporting the work of the global high-energy physics research community. That year, developers at the US National Center for Supercomputer Applications began creating an X-Windows interface for the WWW called XMosaic. Mosaic demonstrated the full potential of the WWW. By late 1993, the WWW began catching on in the popular press. In 1994, Mark Andreessen and other Mosaic developers left NCSA to form Mosaic Communications Corporation, a private firm that later became the firm Netscape. In February of 1995, the WWW was a centerpiece of the G7 meeting of world economic powers.

\footnotetext{
5 Relatively little history of the development of the World Wide Web is available at this point. We appreciate the assistance of Roy Fielding. See http://www.ics.uci.edu/ fielding/socweb/history.html. See also http://www.w3.org/hypertext/WWW/History.html.
} 


\section{The Institutional Coalition}

The Netville of the ARPANET/Internet era was born of the union of two powerful U.S. institutions, the Department of Defense Advanced Research Projects Agency (ARPA ${ }^{6}$ and the academy of research universities and laboratories. Netville grew within an institutional zone of protection that allowed unity to evolve in an otherwise technically and geographically diverse community. The coalition also provided technical and economic incentives to explore the possibilities of the technology, and protected Netville from the interference of other institutions that would have introduced schism and disorder. Two key institutional values held the coalition together and shaped Netville: the demand for technological superiority and the belief in the principle of universal access.

The impetus to develop "internetworking" among organizations can rightly be ascribed to ARPA. ARPA's central institutional value was the maintainence of technological superiority. In the early 1960's ARPA hired the RAND Corporation to conduct a study into methods of building a robust command and control network capable of surviving a major nuclear attack (Newlin, 1995). ARPA's charter under DoD was to direct and fund research that would, when carried to fruition, protect the United States from "technological surprise." ARPA had keen interest in computers. The first computer network system was a DoD effort, SAGE, and there was widespread belief in DoD that computers held great promise for US defense application (Abbate, 1994).

The notion that a computer-supported communications network might help the country in the event of a nuclear attack was only one reason for ARPA's interest, however. ARPA had founded the Information Processing Techniques Office (IPTO) in 1962 to support cutting edge computer research projects in areas such as timesharing, artificial intelligence, and graphics. This work required expensive hardware at each research site, and the requests for even more expensive computers were growing. ${ }^{7}$ By 1964,

\footnotetext{
${ }^{6}$ During its history, ARPA also has been named DARPA, but we refer to the agency throughout as ARPA. This section draws considerably from Abbate (1994).

${ }^{7}$ Abbate (1994) notes that the main IPTO research centers at that time were Stanford Research Institute (timesharing), Stanford Universtiy (artifical intelligence and timesharing), UC Berkeley (timesharing), University of Utah (graphics), UCLA (timesharing), RAND Corporation (graphics), Systems Development Corporation (timesharing), the University of Illinois (supercomputing), Carnegie-Mellon University (artificial intelligence and timesharing), Bolt, Beranek and Newman Company (timesharing),
} 
RAND had produced a plan for a spider web-like network with computer nodes at each intersection, and the capacity for messages to be broken into individually addressed packets and shipped out over the network in a seek-and-find manner to be reassembled at the destination's node. IPTO recognized that this concept could address the nuclear attack problem, but as important to their institutional needs, it could help them deal with the rising demand for computer power among their contractors. Instead of taking computers to each contractor, a network would allow the contractors to come to the computers. Work on the RAND concept was underway soon, and by 1969 the network was named ARPANET after its sponsor.

ARPA had long been in the business of supporting research at leading universities and other academic-like research centers such as RAND. After the RAND report, ARPA began a major development effort on among its major contractors. ARPA and IPTO had long operated in a collegial, academic-like way, and the IPTO leadership had to work to enlist the efforts of its major contractors who were concerned that the network proposal was just a ploy to interfere with contractor work and deny contractors needed computers (Abbate, 1994). Nevertheless, in time a working agenda for the network projects was built around a plan to connect the key contractor sites together. In effect, the ARPANET was to evolve as a physical map of the existing social network structure of IPTO. Much of the early development effort of the ARPANET illustrates the powerful force of the two key managerial strategies of IPTO: the concept of "layering" which meant dividing complex project tasks up into building blocks to be handled by different contractors; and the decentralized management style for which IPTO was noted.

ARPA's quest for technological superiority was matched by an equally powerful need among its academic partners to maintain open access to scientific and technical knowlege within the academy. A key event in the evolution of the ARPANET was the awarding to faculty in the Computer Science Department at University of California at Berkeley in the early 1970's a large grant to develop what would become the key computing infrastructure of the ARPANET. The early ARPANET was conceived, in part, to allow networking among a hodge-podge collection of machines used by various

MIT-Lincoln Laboratories (timesharing, artificial intelligence and graphics), and Harvard (graphics). BBN and RAND played key roles in the early technology endeavors; most of the organizations above were involved in the first fifteen-node ARPANET of 1971. 
contractors. This was necessary to accommodate the different contractors, and it was important for IPTO's scheme to reduce computer costs by bringing researchers to computers. But as a practical matter, the heterogeneity of computers made network building and communication more difficult. The Berkeley strategy eventually focused on the AT\&T UNIX operating system, which had been developed originally as a singleuser version of the powerful MULTICS timesharing system built at MIT with DoD support.

UNIX had a number of advantages as a networking platform, but AT\&T was prohibited from exploiting these advantages due to constraints on it as a regulated telephone service provider. AT\&T refused to license UNIX to commercial companies at reasonable rates for fear of competition by others using their own creation. But AT\&T's attitude toward universities was different. UNIX had been developed at Bell Laboratories, a highly academic research center, with close ties to the university community. AT\&T released UNIX, including source code, to universities for essentially no cost, thus making one of the most powerful and innovative timesharing systems available to university researchers. Of equal importance to the future of the ARPANET, Digital Equipment Corporation (DEC) had released a line of powerful mini-computers on which UNIX would run. DEC had been involved in networking research for some time. It also had been started by two academics from MIT, and the company followed very generous policies for donating and discounting their powerful PDP-11 (and eventually VAX) machines.

A confluence of powerful forces thus leveraged Berkeley's role in ARPANET development. The generally relaxed and collegial IPTO tradition provided researchers with support and left them free to pursue their interests. AT\&T provided UNIX source code and licenses at low cost, and permitted modifications and variations on its product as long as they were for educational and research purposes. DEC provided Berkeley and other computer science departments with free or low-cost UNIX-capable computers of great power and flexibility. The Berkeley faculty were already socially networked to other university computer science departments, through the "invisible college" (Crane, 1972; Pickering and King, 1995). These social networks kept communication flowing, including communication related to the evolving ARPANET project. As the Berkeley researchers and developers adapted UNIX for ARPANET support, they distributed their developments to others in the social network. As the computer network itself grew and became more robust, it became the distribution vehicle through the social 
network, and Berkeley became a key site for distribution of essential technology such as UNIX sources, technical information, and documentation required to keep the existing nodes going and new nodes growing. Before long, a significant virtual community within the invisible college had been built to explore, construct, maintain, and exploit the evolving network. Netville began in the small among the relatively closed community of IPTO contractors, but Berkeley's establishment of UNIX running on DEC machines as the backbone of the network enabled Netville to spread rapidly through university computer science departments. This phenomenon might well have been history's first virtual urban sprawl.

Netville's shared focus on exploration of emergent technological opportunities stands in sharp contrast to most R\&D efforts to create an envisioned artifact according to some developmental "life cycle." The Netville developers built their world around themselves, piece by piece, in response to their environment. New developments arose from the continual growth of the network of machines and users, which brought both an almost continuous demand for cooperative work to solve emerging problems and a continuous supply of new talent to solve the problems. Netville was developed by enthusiasts, interested in the technologies of computers and digital communication, working to solve problems they found interesting. Neither the problems nor their solutions were entirely technical; Netville flourished because it evolved solutions to social problems in tandem with solutions to technical problems. This combination of technical and social endeavor provided the core of the concept of cyberspace (RFC 1118; RFC 1173)

Collectively Netville members comprised a diverse geographical and technical group. Members of Netville originally came from research universities and laboratories spread across the United States, and subsequently across continents. Typical members of Netville were socially bound by institutional ties to their emerging discipline of computer science, and to their universities as undergraduates, graduate students, systems administrators and faculty, or to the military and commercial firms that were part of the evolving ARPA networking scheme. Soon, others such as high school students, former university students, and colleagues in the non-defense commercial sector, managed to persuade systems administrators at these institutions to let them have accounts, and they became members of Netville too. The technical diversity of Netville was due to the great variety of computers and operating systems being used by members of the growing community. This diversity in a planned, top-down 
implementation effort might have precluded rapid growth. In the loosely structured, flexible community of Netville, the diversity necessitated, and thereby also facilitated, the development of workarounds that allowed distributed work toward a common purpose.

It is tempting to think of Netville diversity as ratification of a libertarian ideology of individualism triumphing over government-imposed order. In fact, the members of Netville were government-supported community participants in a vital coalition of the military/industrial/university (MIU) complex that enabled all coalition members to develop common values and work together, smoothing over the heterogeneity each embodied (cf. Leslie, 1993). This coalition began in 1948 with the collapse of the pacifist wing of the Democrat party and the collapse of the isolationist wing of the Republican party, producing a bipartisan, activist coalition pursuing the newly articulated foreign policy of communist containment. This coalition brought two powerful stimuli to the MIU complex: great sums of money, and an intense expectation of extraordinary performance. The Cold War was being fought in earnest, and the task of the MIU complex was to strengthen and protect the national interest through maintenance of technical superiority. The military and other government agencies enlisted to fight the Cold War provided money to research universities and laboratories. Under this arrangement, the military received products and ideas from the industry and the academy, while the industry obtained contracts and the academy obtained funding to undertake interesting and challenging research projects and support bright students. Different government agencies played different roles in the MIU complex, but the primary patron of academic research in computer science was ARPA.

The coalition between ARPA and the academy encouraged Netville to build the network in two ways. First, ARPA provided sufficient equipment and funding to researchers to explore the possibilities of networking technology over an extended period of time, without the hindrance of contract deliverables and deadlines. Netville members were given machines, communication lines and the time to explore and develop networking. Second, the coalition protected Netville by hiding its developments from other institutions such as the market and regulatory bodies that might have influenced the directions the network took. Netville members did not compete to produce solutions as they might have in a market situation. Instead they shared partial solutions, worked cooperatively on each others' software and then made the results available to everyone. The standards they adopted were not subject to any 
external regulations. In contrast to a market/regulation regime, in which anticipatory standards play crucial development roles, standards in Netville developed in an organic manner through informal communications and, eventually, through a generally collegial ARPA-supported authority called the Internet Engineering Task Force (Crocker, 1993). ${ }^{8}$ By protecting the borders of the great divide in which Netville worked, special institutional interests within the MIU complex created a temporary and sheltered zone of opportunity in which Netville members themselves defined the criteria of success. In short, the Netville community was given a chance to construct its own reality -- an almost unheard of opportunity in the market/regulatory regime.

The character of the ARPA/Academy coalition played a critical role in defining the way in Netville conducted networking research. ARPA provided money and a demand for performance, but it was less interested in the process of research than in results. This left the academy free to use ARPA's resources and its demands for performance to define the manner of network research. The leading academic members of Netville soon established as routine the social conventions of "open science" common to academic research institutions. Under the influence of these principles Netville adopted three core values: intellectual curiosity, informal meritocracy, and what we call an egalitarian presumption. Intellectual curiosity meant that finding a new or better solution to a problem was its own reward; cost-benefit analysis was never the first criterion. Status was based on merit, which was based on performance as judged informally by peers: those who developed solutions that "worked" received distinction within Netville, with rewards such as assignment of "guru" 9 status among the other developers. The egalitarian presumption was embodied in a tradition of accepting any person to the Netville community, from whatever background, as long as the person could do good work. Technical expertise, as measured in comparison to other community members, was the passport for entrants to Netville. These three common values enabled the group, otherwise heterogeneous and distributed, to communicate and work together in an efficient and effective manner.

\footnotetext{
${ }^{8}$ The standards that Netville created and followed began as treaties, which only through their adherence to them turned into standards.

${ }^{9}$ According to the dictionary, a guru is a teacher or a mentor. In the computer science world, anyone with a intimate understanding of a particular system or machine often makes their skills known as a "guru" capabilities. Gurus usually help others with problems related to their topic of special knowledge, and are sometimes widely known for their expertise.
} 
One consequence of Netville's adherence to these principles was the emergence of an ethos of open access to the network. In part this open access principle was an extension of the open science assumption of easy access to academic literature. In the case of the network, the concept was extended through the meritocratic and egalitarian features of the community that required easy access by all who might contribute to the cause of building superior technology. Access was necessary both to make improvements and to share them, and perhaps as important, access enabled far-flung members to earn respect within the Netville community and thereby gain the social benefits so important to Netville's voluntary contributors. Open access brought problems, however, and required implementing rules of play to govern behavior of community members. Rules of play were the conditions to which all members of Netville should adhere while contributing to the development of the network and benefiting from the work of others. It was the rules of play that ensured that the technologies of the emerging Internet remained interoperable. For example, Netville adopted a rule under which all sites connected to the network would follow a specific format for packaging of electronic mail messages. Rules of play constituted conditions for entry and continued presence, and were not negotiable. Yet the rules themselves had to be maintained flexibly in order to honor the goal of technological superiority. Freezing conventions and standards too solidly would retard adoption and deployment of improvements in the network.

Maintaining effective rules of play in a dynamic and evolving game was perhaps the most daunting of Netville's challenges. A balance had to be struck between imposing the order required to maintain functionality and growth in the community through addition of new members, and the mandate of technological superiority that required constant, disruptive improvements in the network that bound the community together. The balance was achieved only because the collegial governance structure of the community adhered to a "lowest common denominator" principle, in which functionality was maintained by facilitating gateways, workarounds, kludges, and tricks to enable heterogeneous computing and communication systems to interconnect. There was no effort to make the overall network "efficient" in the sense of optimizing performance at the local or global levels. The performance of the local level was left entirely to the locals, who could join the larger Netville community by adopting a relatively simple, albeit changing, regime of technical and social conventions. The global level was heavily subsidized but relatively unconstrained with respect to expectations, so it could respond in a flexible manner to the needs of the locals. The 
voluntary nature of network membership enabled the powerful streamlining mechanism of self-selection, in which those who wanted to play joined and accepted the rules, and those who did not did not.

In all, the remarkable success of Netville was due to the unlikely but fascinating marriage of institutional interests that were complementary in just the right ways. The impetus and solidarity provided by the Cold War, channeled through the mechanism of ARPA, provided large amounts of money and a strong expectation of performance at the frontier of technological development. However, unlike heavily bureaucratized "procurement" programs, ARPA's patronage left the construction and maintenance of social conventions required to deliver the hoped-for technology to the technological community itself. The dominance of the technical community by academic computer science resulted in the establishment of powerful principles not always found in technical development efforts: intellectual curiosity as a key incentive to the work, suppressing "mission goals" in many cases; informal meritocracy as the core performance evaluation mechanism; and a presumption of egalitarianism that, together with the meritocratic ideal, required open access to the network. The heterogeneity of the Netville community, together with the challenge of maintaining network order while pushing the goal of technological superiority, required the creation of flexible and informal social governance schemes that would probably not have been feasible under a more formally organized program. While some might argue that the ARPA/Internet succeeded in spite of Netville's "disorganization," it is much more likely that studied disregard for formal organization was the key to its success. Netville was, in fact, highly organized at the lowest levels through powerful social conventions sustained by the key institutional forces of ARPA and the academy. This embedded organizational strength of Netville, brought to bear in a dynamic and evolving manner without the distortions of top-down "corrections," is perhaps the greatest innovation of Netville.

\section{Emblematic Developments in The Rise of Netville}

In this section we explore three significant, interrelated developments in cyberspace: the utility of electronic mail, its underlying infrastructure the Transmission Control Protocol and Internet Protocol (TCP/IP), and its superordinate social convention the Domain Name Service (DNS). We demonstrate how the institutional principles and predilections discussed above shaped the way in which these systems were built. The examples substantiate our belief that these systems were affected by the institutional 
coalition in three ways; they were typically built in response to emergent problems, they were not planned, and they comprised of both technical and social solutions.

Electronic Mail. Person-to-person electronic mail, the most rapidly adopted utility on the ARPA/Internet, was not part of ARPA's original network plan. ARPA had two agendas for the network. From a military standpoint, it sought a robust, distributed, asynchronous, autonomous communication system capable of surviving massive nuclear strikes. This was a "proof of concept" objective, aimed at showing whether or not such a communication system could be built. From a more pedestrian defense research management standpoint, it was searching for a way to aggregate the efforts and costs of geographically dispersed researchers. This was a practical objective, tied to the political chore of justifying ongoing research investments in expensive computing infrastructure for ARPA researchers. The network was seen as a mechanism for cost saving by allowing distributed researchers to share computing resources through file transmission protocol (FTP) and remote login capabilities.

The academic researchers charged with the development of the network had experienced electronic mail on multi-user computers, and saw extension of the utility to different research locations as useful to research across the network. Systems administrators in the research domain had already begun to try to get the computers they ran to communicate so people could send electronic mail locally, but this was difficult due to the variety of different machine platforms. Through sharing of expertise and ideas, researchers at local sites acquired the know-how to connect local machines together, and in time they linked their sites to others across the network. By the early 1970's users of the ARPA/Internet were communicating with each other on a regular basis over the network. The members of Netville, still a small community, used informal agreements to ensure that everyone could read the messages sent across the network.

Over the following ten years the number of machines connected to the network grew. The decreasing technical costs of joining and the lure of the Netville community brought more machines and more people. By 1983 ARPA split the network up into two parts, MILNET, the military network and the ARPANET for research, together 
comprising the ARPA Internet. 10 The Netville leadership realized that growth would bring the need to standardize electronic mail formats to allow everyone to communicate with everyone else on the network. Increasing diversity of machine types and participants would soon overwhelm the informal standards process, leading to incompatible electronic mail domains. Using the network itself as the platform for discussion, Netville community deliberated for a year before agreeing on the simplest format, the memo (RFC 822). The memo became a formal rule of play, a lowest common denominator standard to which all mail systems must comply (Crocker, 1993). They recorded this in a working document, the Request for Comments (RFC) 11 that served as an on-line document of the standards in use (Comer, 1991). This allowed a wide range of mail readers to be built that would run on different kinds of machines, but still be compatible with each other.

By formalizing the rules of play for electronic mail, Netville created the opportunity for individual sites to develop their own systems and principles for electronic mail communications. Different mail handlers including MH, Berkeley Mail and R-Mail were developed and deployed, and the administrators at the distributed sites worked collaboratively with each other to develop state-of-the-art electronic mail applications that they subsequently maintained for multiple sites on the network. New system development was not a condition for continued use of the network, but many systems administrators adhered to the principle that users should help advance the field. In this way the distributed community of Netville members reinforced the principle of seeking technological superiority across the network.

\footnotetext{
${ }^{10}$ An Internet means multiple networks. An Internetwork. At this time there were two, the ARPANET and MILNET.
}

${ }^{11} \mathrm{An}$ RFC begins life as a request for comments made by an individual or site concerning a change which they believe should be made to the network. These are then discussed by the developer community, anyone who chooses to have an opinion. Finally, when agreement is reached these documents are kept as the standards documentation which informs Netville of the new change. Everyone is expected to observe the new changes (Crocker, 1987). The history of RFCs is well captured by a quote from Vinton Cerf:

"In April 1969, Steve issued the very first Request For Comment. He observed that we were just graduate students at the time and so had no authority. So we had to find a way to document what we were doing without acting like we were imposing anything on anyone. He came up with the RFC methodology to say, Please comment on this, and tell us what you think." (Cerf, 1993). 
TCP/IP and DNS. The development of electronic mail was crucially dependent on two socially constructed, complementary components of the broad network vision: the Transmission Control Protocol and Internet Protocol, collectively known as TCP/IP; and the Domain Name Service, or DNS. Through TCP/IP and DNS the users of any given machine could inhabit Netville by communication with other machines and other people. Ideally, any would-be Netville member could easily connect his or her platform to the network. This was a "low-barriers-to-entry" vision that required a set of technical rules of play that would specify exactly how all data would travel across the networks, and how addresses were to be constructed and normalized.

$\mathrm{TCP} / \mathrm{IP}$ was an essential component of the networking vision (Quarterman, 1993). The IP defined the data to be sent across the network by sorting information into standard packets that could be transmitted. Under IP each "host" machine was given a unique IP "address," a number to which could be attached attendant routing information. TCP was developed to support IP by providing a reliable mechanism of sending data over the network from one machine to another (Comer, 1991). In addition to the important task of supplying funds to develop the TCP/IP standard, ARPA, moved its own machines to TCP/IP. This soon brought other researchers doing work with ARPA to adopt TCP/IP so their systems could link to ARPA systems. Without direct mandates, ARPA influenced the setting and adoption of the TCP/IP regime that became a vital component of Netville's infrastructure. The establishment of TCP/IP as a "standard" occurred with the release of Berkeley Software Distribution (BSD) UNIX 4.2 that incorporated TCP/IP (Quarterman, 1993). BSD made its software available to other research institutions at distribution cost, ensuring the rapid spread of BSD's TCP/IP implementation among academic computer science systems administrators already familiar with and partial to BSD UNIX (Quarterman, 1990, King, 1991). It is estimated that the release of BSD UNIX 4.2 alone resulted in the conversion of $90 \%$ of academic computer science departments to TCP/IP (Comer, 1991).

Once TCP/IP was established as the standard for network membership the demand for IP machine addresses went up rapidly. Machines running TCP/IP required an IP address, and this address had to conform to three conditions: it had to conform to an exact format so as to be recognizable throughout the network; it had to be unique so messages would go to the right places; and it had to be formally registered to enable universal and consistent distribution of address tables throughout the network. The distributed Netville community could never expect to exert such exacting control over 
the vital task of addressing; once again, ARPA aided the Netville cause by assigning the ARPA-supported Network Information Center (NIC) the duty of managing the assignment of IP addresses to new network members (Baker, 1993). Anyone who wished to connect a machine to the network would register their machine with the NIC in order to acquire their unique IP address.

In principle, address control was simple because IP addresses are built from a straightforward numbering scheme that was tractable in network management terms. Unfortunately, an IP address such as 128.10.2.30 did not give much information to Netville members who were trying to communicate with individuals at specific sites. Netville users desired that addresses be accompanied by names: for example 128.10.2.30 could be called localhost, and localhost in turn could have other information attached to the name to designate the institutional location of the address (e.g., a specific computer science department in a given university). Adding naming to IP addressing was not a major technical challenge -- one simply assigned given addresses specific and unique names, and the resulting tables were used to route messages to the right locations. However while Netville members might be indifferent to the IP address their machines received, they were very particular about the names they used, and they usually wanted to pick their own names. A larger population of names increased the problems of redundancy -- a disaster in addressing schemes. In addition, addition of names substantially increased the work involved in updating tables, since every machine linked to the network had to be updated when each new host was added. System administrators at each site bore the brunt of this work, and soon demanded that something be done to reduce the load on them. Netville's solution was to create a new set of rules and principles implemented in part with a technical solution called the Domain Name Service, or DNS (RFC 882).

DNS structures the assignment of names on the network and converts those names to their unique IP addresses. It enforces a formal naming convention through the concept of domains, which are authority zones within which specific host machines reside. The domains are organized hierarchically when possible: for example, within the "education" domain (edu) a given university is a subdomain, a department within that university another subdomain, and a given machine the local host; for example, localhost.csdept.stateu.edu. Table 1 shows the common formats agreed to for the types of organizations. For each type of organization, a technical system known as a name 
server that knows about the organizations and machines connected to it. ${ }^{12}$ When a packet arrives at the name server the IP address of the machine that correlates to the name is located and required information is sent back up the chain until the address becomes known. These servers work collaboratively to decode the entire name and translate it into the correct address (Krol, 1993). This solution had the advantage of controlling the naming at the higher level of organizations shown in Table 1, while allowing choice in names at the lower level domains as long as there were no addressing conflicts identified by the DNS. In the case of conflicts, precedence typically determines the outcome: the first organization to claim a name usually gets to keep it. This has led to controversy, as individuals moved early to register names such as mtv.com that could be mistaken for widely recognized company addresses. 13

\begin{tabular}{|l|l|}
\hline Name & Meaning \\
\hline \hline gov & Government Organizations \\
\hline .edu & Educational Organizations \\
\hline. mil & Military Organizations \\
\hline. com & Commercial Organizations \\
\hline .net & Network Organizations \\
\hline .us .uk.au etc... & Geographical Location \\
\hline org & Other Types of Organizations \\
\hline
\end{tabular}

Table 1: Standard Type of Organizations (Comer, 1991)

\section{Success in the Great Divide}

The examples above demonstrate how a desire to achieve and maintain technological superiority and universal access shaped the development strategy of Netville.

\footnotetext{
${ }^{12}$ We have explained DNS in its conceptual format. The technical reality of the system means that each name server actually holds much larger parts of the naming hierarchy than the conceptual model implies (Comer, 1991). The conceptual model makes understanding the relationship between servers much easier to understand.

${ }^{13}$ The cable television network MTV has in fact sued a former employee who retained the Internet name $\mathrm{mtv}$.com before the network had any interest in the Internet, demanding release of the address to the company (cf. New Multimedia Reviews, January 27, 1995).
} 
Electronic mail began life as a vision of a technical system to be used by Netville members to build and maintain their community. The drive for electronic mail eventually required Netville to abandon at least some of the dream of local autonomy and develop rules of play by which members at any site with suitable hardware and software could join the community. TCP/IP was created to facilitate ease of access as well as reliability in the network, and the DNS was created to establish and maintain order in the vital area of addressing. These reforms did not simply happen: they were borne of the institutional coalition of ARPA and the Academy, through the values, guidelines and protection those institutions offered Netville.

These vital developments occurred as community movements, galvanized through the coordinating authority of key institutional players. None of them followed a software "life cycle" of development, with extensive requirements analysis, specification, and so on. Indeed, they were created with a remarkable and refreshing lack of concern about "methodology." They arose in response to environmental conditions, most commonly the shared problems of the ever-growing community of network users. Somehow the resolution of these problems maintained a balance between the need for communitywide coordination and local autonomy to facilitate innovation. Innovations evolved not by pursuit of a formal planning and development process, but through informal discussion about visions and solutions, supported by a flow of partial solutions through the network. As members learned about the issues they posted questions and suggestions, and when possible sent replies recommending hacks and fixes. Community members designed patches for each others' software, emphasizing a culture hacker-driven ${ }^{14}$ computer supported cooperative work. What makes Netville particularly fascinating is that it was sui generis: a computer supported cooperative work project that got its start as an effort to build the computer support network through which the CSCW would take place. Netville was literally a case of the mechanics making their own tools.

Netville ended up building more than just solutions to technical problems; they also ended up designing solutions to social problems. These social solutions were developed out of necessity through on-line discussions, through resolutions recorded in

\footnotetext{
${ }^{14}$ We use hacker in the original sense of the meaning, someone who develops code by continually iterating versions and testing. We do not imply that they behaved unlawfully or intended any harm to other systems, as hacker has come to mean subsequently.
} 
RFC's, and through the establishment of rules and principles to govern the actions of their members. Netville members were clearly technically proficient, but they proved to be socially proficient as well, and it seems likely that the technical innovations of Netville could not have occurred without some of the social innovations they developed. But behind every innovation lies a vital context of institutional factors that at the least enabled and arguably encouraged particular social innovations. The curious mix of institutional forces in the MIU nexus, and in the ARPA/Academy coalition, sheltered and facilitated the social innovations that make Netville so fascinating. ${ }^{15}$

Star (1993) argues that living in the great divide requires managing the paradox of building a unified community where the prevailing ideology is the maintenance of heterogeneity. Netville accommodated the paradox, and in so doing built the Internet, an "open system" where no one "owns" the fundamental vision and everyone gets to participate, but an ordered and regulated world in which certain rules are enforced with great care (Comer, 1991). The institutional coalition between ARPA and the academy provided the social-glue which Netville leveraged from in order to create the network. The goals of technical superiority and universal access encouraged individual Netville members to innovate, but within an understood set of constraints required to maintain openness. Netville's rules of play were not unlike Star's distributed passage points that bind heterogeneous actors through a common language, a series of structural and symbolic means of ordering and controlling the action. Using this common language, Netville defined and built technical solutions to problems of transportation, TCP/IP, communication, electronic mail and USENET, and notation systems, DNS, for all network users.

\section{THE FALL OF NETVILLE}

Any enterprise that arises in the Great Divide, even if enabled by the Great Divide, remains vulnerable to the dangers inherent in that divide. The powerful alliance of ARPA and the academy made life in the Great Divide sustainable for a time, during which Netville enjoyed an unmolested development domain. The Great Divide, by Star's characterization, can be mistakenly seen as a desert, devoid of life. But it is not so

\footnotetext{
${ }^{15}$ Netville's accomplishments are impressive, but they should not be seen as historically unique. Other communities, out of necessity, have developed highly elaborate technical and social solutions to the problems of exchanging information necessary to common enterprise (Forster and King, 1995).
} 
in any a priori sense. The Great Divide is barren as a matter of choice by those communities that border it; they make it a desert by refusing to occupy it. This disregard for the activity in the divide gives inhabitants of the divide a peculiar freedom. In time, members of adjacent communities become attracted to the activity in the divide, and moved into the divide to colonize it. In the late 1980's new and powerful institutional forces that were previously ignorant of, or at least indifferent to Netville and its accomplishments began the process of colonizing the Divide. By 1990 the fall of Netville had begun, illustrated by a mechanism we call "patron swapping."

Institutional patrons such as the DoD, ARPA, NSF, and the academy played crucial roles in shaping Netville. But the relationships among these patrons were never very stable, and over time the key financial responsibility for supporting the Netville community wandered from one institutional player to another. In the middle of the 1980's the institutional role of ARPA with respect to Internet-type networking began to decline relative to that of other organizations. This might sound strange, given that ARPA played such a key role in the creation of Netville. Why did Netville not become a military-dominated bureaucracy, or at least a separately-governed bureaucracy subservient to the military's needs, as some of the Department of Energy's laboratories are? The answer, we argue, is that Netville had served the first of ARPA's needs: it had constructed the desired packet-switched network technology ARPA wanted to see proven, and it was possible for ARPA and the DoD establishment to take networking "in house" for their needs without further involvement by Netville.

Equally important, Netville both directly and indirectly met ARPA's need for linking its academic research community together. By the mid 1980's it was clear to ARPA that once the researchers were hooked together they would remain connected whether or not ARPA paid for the connection. The ARPANET had become an important vehicle for communication among academics with access to it. As Pickering and King (1995) have suggested, there have long been strong incentives in the research community to exploit technologies that facilitate weak-tie social network maintenance, and electronic mail over networks was an excellent technology for this purpose. The research community, including those working for DoD, would keep their networks operating. Considerable additional impetus was provided for networking in the academic world by the contemporaneous development of grass-roots networking enterprises such as 
BITNET and CSNET. 16 These network enterprises had emerged to link faculty in business schools, non-ARPA funded computer science departments, and other university departments. These networks subsequently linked many European research institutions together as well. In the mid-eighties gateways between these networks were created, and over the next half of the decade all of the major network initiatives would be folded into the Internet. By the late 1980's there was a broad cross-section of commercial and research institutions connected together, but still Netville owned the most significant development rights to the network.

In 1990 ARPA, long a vital patron of Netville, signaled its clear intentions to withdraw. The age of the Internet arrived, and with it a new constellation of institutional forces. From this point onwards the character of the Internet began a slow and irrevocable change, from a research network to a more commercial successor. Slowly but surely the founding institutional coalition disappeared from the network, leaving Netville's borders open to new influences. Some of these were very much like the earlier academic forces -- the non-computer-science academic communities enabled by the bigscience networking initiative within NSF and the ancillary expansion of networking into campus computing centers that brought in the Humanities, Social Sciences, and so on. Much more important, however, was the rise of commercial activity on the net. Initially this was in the form of active participation of the research divisions of for-profit corporations as users of the network (Kahin, 1990). In time, however, this grew into a much more serious matter. For one thing, use spread well beyond the research divisions into the general departments of such organizations, so the Internet became a more general-purpose network. Perhaps most significant, commercial companies offering Internet access and services entered the picture, such as Prodigy and America On-line, bringing the Internet into the home. Internet began to be advertised as a place

\footnotetext{
16 The story of BITNET and CSNET deserve a full accounting elsewhere. Briefly, BITNET, which stands for "Because It's Time NETwork," grew out of IBM-sponsored network innovations among a number of academic business schools, and eventually grew to encompass a great many academic disciplines. CSNET was an NSF-sponsored program to extend ARPANET-like access to the academic computer science community not formally a part of the ARPA research structure. CSNET is particularly important because it was a key factor in the networking component of the NSF Supercomputer Centers initiatives that located powerful computers at distributed locations throughout the US. The NSFNet backbone of high-speed links that tied these centers together provided the essential trunks for rapidly growing network traffic during the explosive growth in the Internet in the late 1980s and early 1990s. NSF has since backed away from support of the Internet trunks, and the infrastructure at this point is largely privatized.
} 
to meet people, to ask questions through the bulletin boards and distribution lists, to find answers, and to do business. Many new users joined, inspired by the visions of thousands of users on-line, and encouraged by the cheap and readily available technologies. The hype of the "information superhighway" finally was crystallized by the newly elected Clinton administration in 1992 (King and Kraemer, 1995).

Some idea of the significance of this growth can be seen in Figure 1. The long-standing use of the educational (edu) domain has continued to grow, but use by the commercial (com) domain has overtaken the educational domain. The new users of cyberspace have had an enormous effect on the character of the network, and in the process they have profoundly changed Netville. The new users often violate social norms longcherished and adhered to in Netville, either through ignorance, or simply because it is possible to do so without meaningful penalty. The new users also have attracted interest from institutional players not traditionally part of the Netville scene: software development companies, cable TV companies, telephone companies, Hollywood, and so on who wish to grab a piece of the market they believe lies dormant in the Internet culture and surrounding Cyberspace. These new players have little understanding of and or use for the culture of Netville, or the elaborate social conventions and mores that sustained that culture and enabled the production of the very artifacts that so entice them. At the same time, the Internet has attracted groups such as the Computer Professionals for Social Responsibility (CPSR) and the Electronic Freedom Foundation (EFF) who see it as their mission to contest these commercial visions of the future of Cyberspace, often with ideologies close to those of the dying Netville. However, these defenders of Netville values appear to misunderstand the processes that created Netville just as the new commercial players do, and their arguments about building and sustaining a viable, Netville-like social enterprise seem naive. The future of Cyberspace now lies clearly "beyond the Internet" (NAS, 1994).

It seems inevitable that as governmental support for Netville's creation decreases and the commercial and market interest increases, Netville itself will come under new institutional directions. There will be changes in governance structures, which will alter what can happen with Netville, and there will be new objectives. For example, the egalitarian spirit will likely be replaced by some form of equity influence, reflective of capitalist enterprise, and the influence of key players will revolve more around successful product development than on clever expressions of intellectual curiosity. Current Netville members may find room to continue their work, possibly in ways close 
to those they now follow, but they are not likely to experience the same degree and kind of influence over the future of Netville's creations as they enjoyed in the past. The paradigm of exploratory research that Netville grew up with will be replaced by an ideology of efficient production.

There is little doubt that the founding citizens of Netville have lost their ownership of the electronic frontier. Their cozy home in Great Divide is rapidly being colonized by commercial organizations, followed closely by regulators who wish to control access, uses, content, and so on. The citizens of Netville will never regain control over cyberspace. Curiously, the citizens of Netville can be said to have manufactured their own downfall. By developing a technically sophisticated network and encouraging universal access for all, they maintained low barriers to entry to a highly desirable resource. The institutional alliance of ARPA and the Academy created a vibrant space in the Great Divide full of resources and freedom. But the institutions involved never intended to create a new world. The Netville enterprise was a project, like many other military/academy projects, that went before. In time, the project had to end. Whether the citizens of Netville "deserve" the fate that has befallen them is an interesting question. Some of the early citizens of Netville have found very lucrative niches in the new commercial order, and have apparently found happiness doing so. In those cases, they are not complaining but some of their colleagues from Netville days who were not so fortunate might. In any case, the whole Netville phenomenon and what it spawned was unforeseen except by a few visionaries who were not taken seriously, so the question of what it means to deserve the fate of Netville is a troublesome question.

Two futures for Netville seem likely at this point, if one considers the future in a superficial way. In one, Netville joins the list of legendary ghost towns with little but relics and ruins to mark what was once a vibrant and progressive social venture. In this vision, the social glue and institutional strengths that held Netville together are slowly eroded by powerful new interests with different visions and goals, and eventually there is nothing left but the empty buildings and dusty streets of a bygone era. Life goes on elsewhere.

In the other vision Netville evolves in the model of Las Vegas. Las Vegas was a sleepy village until the lure of the Dynamo brought can-do engineers and builders, backed by huge sums of federal money, to build a great hydroelectric dam across the Colorado River at Boulder Canyon. Boulder City and Las Vegas were the construction 
boomtowns of the Hoover Dam Project. Boulder City slipped into oblivion when the dam was done, but Las Vegas did not. Las Vegas capitalized on its rapidly developed infrastructure of vice-filled entertainment, which served the huge dam project, leveraged by the cheap electricity produced by the dam. Brilliant electric lights and a flair for naughty-as-nice brought Las Vegas from construction boomtown to entertainment capital. Few of the old engineers and construction workers were visible in the resulting glitter, but Las Vegas lived on. Some of the Netville wizards have already gone on to their fortunes, having commercialized and exploited those elements to which they could lay claim. It is easy to imagine Netville's future as similar to that of Las Vegas -- an icon in a new age of altered social mores and values, released by the power of new technology, in what was once the desert of the Great Divide. In this view, Netville will live on as a shining but distant and distorted reflection of former glory.

The ghost town and boom town scenarios are compelling visions of how the future of how Netville will evolve, but they do not offer any specific explanations about the challenges Netville faces if it is to survive in the new order. ${ }^{17}$ They also do not reflect some of the nuances that are likely to govern whatever happens. We argue that Netville is much more complex than either of these explanations suggests. It has been a construction boomtown, and probably shares some of the fate of former boomtowns. But it is also a strange and heretofore unseen thing: an on-line development community that was built around the very artifact it was seeking to build. In this section we outline some of the factors that may work together to affect the fall of Netville.

We are watching the dissolution Netville as it is happening. Much of what we think will be important is necessarily speculative, making it impossible to offer empirical proof to support our claims. We must therefore offer an assessment of the ongoing changes in light of the fact of patron swapping noted above, and the implications of this for what we believe to be central values that caused Netville to arise as it has.

Presumably, if these change, Netville will change. We focus on phenomena that will produce profound changes in Netville values: proprietary fame, the loss of novelty, and the rise of path dependency .

\footnotetext{
${ }^{17}$ Boomtown is becoming an increasingly popular metaphor for describing how the Internet has grown in the last few years. A recent description of the initial public offering by Netscape Communications Corporation says: "So what exactly was America buying into with such enthusiasm last week? The Internet, of course, that boomtown of the wired world." (Quitner, 1995).
} 


\section{Proprietary Fame}

The ARPA/Academy nexus of Netville was not concerned with and did not enable a strong connection between genuine equity rights in development of new technology and the fame that might attend such contributions. All the efforts of the enterprise were owned by the institutions that supported the work, not by the individuals involved. And, unlike the field of physical technology developments where fairly sophisticated patenting schemes have evolved to provide rents to inventors, universities, and government from such research, much of the Netville work was in the realm of ideas and software that are not easily patentable. Besides, the focus of the work was anchored by the "public goods" goals of defense and the creation of new knowledge. It is doubtful that many of the early participants in the Netville community realized the downstream commercial potential of their work.

This condition has changed dramatically. Not only has the old ARPA/Academy alliance evaporated, the commercial world has stepped in to take the lead role. A host of companies have begun to offer commercial products related to the evolving networks. Netscape is perhaps the most celebrated example of this, wherein a key developer from the traditional Netville community took the knowledge he gained creating the Mosaic network browser -- a product owned by the National Center for Supercomputer Applications, a noted Netville entity -- and constructed a new propriety browser with improved performance. He initially distributed this product as shareware, and once it was established, he and his investor partners began selling the product. When a stream of revenues was reached, they and created a new public company whose shares increased in value by an order of magnitude in a few months. There are many similar examples. Netville thus departed the era of performance fame and entered the era of proprietary fame. Performance is still a key factor: Netscape's success as shareware was surely due to its superior performance compared to Mosaic. But fame in Netville shifted from recognition of a technical job well done by colleagues who also are developers, and to recognition by a consuming public voting with their dollars. 
Proprietary fame clashes with core values shared by members of the Netville community. These new technologies are not shared for free, as in the past. ${ }^{18}$ It is essentially impossible for a market to emerge where products are shared at no cost to their consumers. An ethic of market choice that depends on price/value comparisons cannot emerge due to lack of pricing. In Netville value was a key focus, and to a remarkable degree value was linked to an amorphous ethic of intellectual curiosity in which clever ways to solve problems was cherished. Netville members shared their development efforts around the Internet, not only to end users, but also to other developers who could and did make important additions to and modifications of the products. Ownership was recognized as a matter of professional courtesy than as subservience to equity rights that imply authority to collect rents. The advent of proprietary fame deprives Netville members of access to the product itself through imposing the rule of property rights, backed up by a huge institutional establishment that protects them. At the practical level, members who might formerly have jumped in to improve the new products released in Netville face the obstacles common to proprietary software, particularly code that is hidden behind interfaces or otherwise inaccessible to tinkering.

Proprietary fame also deprives members of the Netville community a sense of participation in the vital "cool" new technologies that are being built and released, and destroys the old Netville culture of informal meritocracy through which even otherwise low-status members could find fame quickly. In the past, a clever developer could make a prominent mark in the Netville community simply by providing a technological trump card. There was little concern over the possible theft of the new technology because there was basically nothing to be done with the technology outside the community. This encouraged sharing. There were low barriers to access by other community members, who could request and receive the source codes from their colleagues and hammer on the new products to see how good they really were. Genuine breakthroughs were quickly recognized through such testing, and their developers could gain fame overnight .

\footnotetext{
${ }^{18}$ Netscape offers free copies of its browser for academic use. However, despite offering free copies for individual use, the company does not encourage the members of Netville to extend and build upon their product.
} 
Proprietary fame alters the culture of informal meritocracy in key ways. For one thing, it makes it nearly impossible for such a culture to emerge or be sustained. Concern over theft makes it foolish to release new technology without adequate protection of intellectual property, which greatly reduces both provision and access. It also greatly raises the barriers a developer faces in getting innovation into the community. In order to penetrate the wall surrounding the zone of proprietary fame, a developer must acquire financial backing to buy expertise necessary to protect the property and distribute it in a manner that allows rents to be collected. Of course, a developer could still just give away his or her hottest ideas on the grounds that they are good for the community. But without the right protection on those ideas, which can only be created by experts the developer might not be able to afford, there is nothing to prevent an enterprising user from appropriating the ideas and implementing them in a manner that allows the collection of rents. The original developer becomes a chump in such a situation: a factor that discourages such altruism. It is one thing when the community benefits from an idea but no one, including the innovator, gets rich. It another thing altogether when someone who did not create the innovation gets rich by appropriating it while the innovator gets nothing. This further offends the old ethics of Netville in which technical superiority was respected in ways that clever marketing never could be. 19

Proprietary fame also greatly alters the sensibility of the Netville community by giving developers a stake that they feel they must protect. Unlike in the old Netville community, where costs of innovation diffusion were low and fixation on standards was limited to keeping the vital network running, the new order of proprietary fame creates an incentive for product developers to force standardization as a weapon to freeze innovation around their products and erect barriers to entry by new innovators. This kind of standardization is a great departure from the former, lassiez innover ethic in which standards were a necessary evil. Establishment of a proprietary standard can lock in a small group and freeze out a potentially large group of contributors. This can happen even without clever scheming on the part of the proprietary standards providers. Sometimes it simply evolves. A good example is provided by the evolution of the World Wide Web (WWW), in which a long-standing community of hyptertext

\footnotetext{
${ }^{19}$ Mark Andreeson, developer of Mosaic and Netscape, is a notable exception to this scenario. He proved his technical prowess before cashing in on it. In the ethics of Netville, he at least deserves what he has gained. It is doubtful that less technically creative people could obtain the respect of the Netville community while getting rich off its innovations.
} 
researchers who were concentrating on workstation-based systems were displaced by another group that happened to be building an Internet-based implementation of hyptertext functionality. Even if the WWW developers had no idea they were displacing the traditional hypertext community by their actions, the traditional community still resents being left out of a revolution they feel, with some justification, they helped to start. Proprietary fame thus creates classes of winners and losers that could not have evolved in the old culture of Netville.

\section{The Loss of Novelty}

The Netville community was once the frontier of electronic communications and internetworking. They were wildly successful, realizing their visions of a networked world. Although their creation has much room for innovation remaining, as shown by the WWW transforming the character of the Internet by taking it into color, sound and graphics domain, many of the research questions that drew Netville members have been mined out, and the new questions to be answered have a very different institutional character. They are interesting, but they are not novel. And the loss of novelty will greatly alter the culture of Netville. A good example of this is the shift from concern over how to make the network and its features work to how to deploy network infrastructure at full social scale. The former challenge was basically a research issue, opening the networking frontier. But it was not the first networking frontier to be opened: the networks of electricity, telephony, and so on were deployed over the past century, and the institutional players in those worlds are deeply established. It is quite likely, in fact, that these players (e.g., the Regional Bell Operating Companies, Cable Television Companies, and so on) will be central service providers as internetworking expands. It would be ironic if the flashy new world of cyberspace is deployed through the institutional structure of "plain old telephone service," but this is a very real possibility.

Those who study the long-term social and economic aspects of technical innovation will not be surprised if cyberspace is eventually subsumed under the umbrella of established infrastructure providers. This is a well established phenomenon in the history of innovation. To the Netville community, however, such a prospect is anathema to the central value of novelty that mobilized and motivated their work. Netville was about the cutting edge, the truly new. In a profoundly important sense, the Netville vision of novelty was always on a collision course with the success of 
Netville's efforts. As soon as the networks created by the Netville community went public and started to become commercialized it would be impossible to retain the novelty that characterized the early days. The exciting questions about how to make computers and communications perform this or that interesting feat inspire researchers and engineers. Questions about the character of telecommunications regulatory reform do not. Yet these latter questions address the most important issues that will shape the future of cyberspace. Beyond these, there are the myriad questions related to application, maintainability, and social impact of the networks that typically do not excite engineers, but that are the heart of the future of networking. Loss of novelty, at least as understood by the research and engineering community that gave rise to Netville, is a serious blow to the Netville culture.

\section{Path Dependency}

The challenge of creating new infrastructure is often different from the challenge of living with it. In the same way that the success of Netville was on a collision course with the novelty of the enterprise, success is on a collision course with innovation. Earlier we discussed the development of TCP/IP and DNS that were remarkable solutions to the problems of maintaining heterogeneity while at the same time enforcing some uniformity in Netville. These evolved as treaties among Netville members; they were seen as intermediate solutions to critical problems threatening the work of the community. They were not intended to become standards, and they certainly were not seen as future millstones around the collective necks of Netville developers. Yet one can argue that they have become just that, through the process of path dependency.

Path dependency is a term coined by Paul David to describe the interesting phenomenon of early technologies becoming so established in use that they cannot be displaced by newer, and clearly better, technologies. His case in point is the ubiquitous QWERTY keyboard, designed originally to slow down typing so typists would not overdrive the early mechanical typewriter mechanisms. Although ergonomically superior keyboard designs were developed in later years as typewriters improved and allowable typing speed increased, the QWERTY keyboard proved impossible to displace (David, 1985). The economic costs of overcoming the path dependencies generated by the original design were an insurmountable barrier to later designs. This point is relevant to Netville, because treaties and conventions adopted years ago as convenient and temporary solutions to problems have evolved to be ironclad standards 
that serve powerful commercial interests. Both TCP/IP and the naming conventions that served their purposes well during the Netville era will eventually reach their limits of capacity. Irrespective of whether superior means are available for transferring data, routing messages and naming systems, the technical infrastructure and the beneficiaries of that infrastructure are locked into TCP/IP and DNS. Even assuming the other changes mentioned above were irrelevant, this path dependency alone creates a powerful culture clash for the Netville community by limiting the options for creativity.

The loss of novelty, combined with path dependency, run counter to the premise of innovation-above-all that Netville members held when they set about developing the technology. The rise of Netville was the story of pioneers and explorers. The fall of Netville is essentially the story of the end of the frontier that made pioneering and exploration possible and important.

\section{CONCLUSION}

The fall of Netville is well underway. The Internet has moved slowly beyond the control of the research world that gave birth to it. America On-Line, Compuserve, Prodigy, Netscape, and other inheritors of the Netville mantle are fundamentally different, even if they contain some former citizens of Netville. The network that Netville built lives on, and remains an outstanding achievement. Three decades ago the network was a dream, a hazy possibility, a vision in a few bright minds. The realization of that dream required the creation of the remarkable boomtown of Netville, located in the Great Divide that offered sanctuary and protection from the "centers" of other social worlds. The sheltered world of the Great Divide allowed Netville to prosper in the face of problems and uncertainties. It was not just the skill and patience of the Netville community that brought about cyberspace. It was the enabling condition of Netville's removal from the often over-rated incentives and underestimated constraints of the market that allowed those skills and patience to bear fruit. When the payoffs became obvious, the original patrons withdrew because their missions of technological demonstration and proof-of-concept had been established. New patrons seeking to exploit the riches revealed by Netville moved in. In this process of patron swapping, the seeds of the fall of Netville were sewn. The final end of Netville will come about through the forces of proprietary fame, loss of novelty, and path dependency that radically alter essential aspects of the Netville culture. 


\section{Hosts}

(000's)

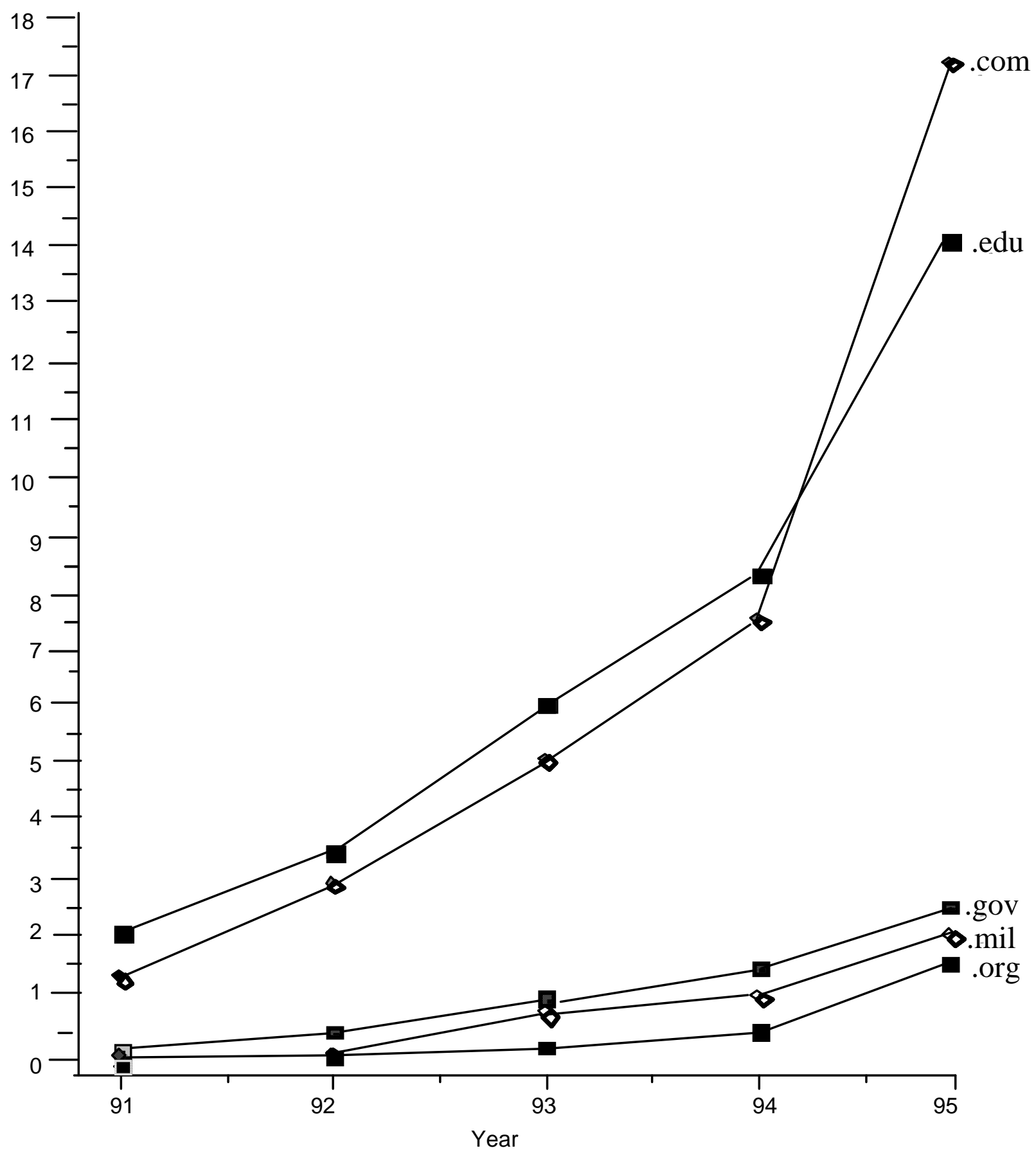

Statistics from Internet Domain Survey http://www.nw.com

Figure 1: Growth of Internet Host Domains 


\section{ACKNOWLEDGMENTS}

We would like to thank David Harnick-Shapiro, Sam Horrocks, Tim Morgan and John Romine for the valuable information which they contributed to the start of this paper, as well as for maintaining our departments' commitment to the network. Dave Crocker, and John Vittal were instrumental in providing insights not available elsewhere. Roy Fielding was key in our efforts to find information on the history of the World-Wide Web. We particularly want to thank Einar Stefferud and Marshall Rose for their vision of networking during their time at UCI, and their collegial insights on the subject. Finally, we thank Lisa Covi, David O'Leary, Ignace Snellen, and Sara Kiesler for their insightful comments. 


\section{REFERENCES}

Abbate, J. From ARPANET to Internet: A History of ARPA-Sponsored Computer Networks, 1966-1988. Philadelphia: University of Pennsylvania, unpublished doctoral dissertation, 1994.

Baker, Steven (1993) "The Evolving Internet Backbone" UNIX Review 11(9):15.

Beniger, J. The Control Revolution: Technical and Economic Origins of the Information Society. Cambridge: Harvard University Press, 1986

Cerf, V. (1993) "How The Internet Came To Be" As told to Bernard Aboba, Internaut Magazine.

Comer, Douglas, E. (1991) Internetworking with TCP/IP Volume 1 Principles, Protocols, and Architecture Prentice Hall: Englewood Cliffs, New Jersey.

Crane, D., . Invisible Colleges: diffusion of knowledge in scientific communities. University of Chicago Press, Chicago, 1972.

Crocker, David (1987) The Origins of RFCS in RFC1000.

Crocker, David (1993) "Making Standards the IETF Way" StandardView 1(1):48-54.

David, P.A. Clio and the Economics of QWERTY. American Economic Review, Vol 75, No 2., 1995, pp 332-337.

DiMaggio, P.J. and Powell, W.W., (eds.).The New Institutionalism in Organizational Analysis. Chicago: University of Chicago Press. 1991.

DiMaggio, P.J. and Powell, W.W. The iron cage revisited: institutional isomorphism and collective rationality in organizational fields. American Sociological Review, 48:147160, 1983. 
Forster, Paul. W. and King, John Leslie. Information Infrastructure Standards in Heterogeneous Sectors: Lessons from the World Wide Air Cargo Community. In Kahin, Brian and Janet Abbate (eds.) Standards Policy for Information Infrastructure. Cambridge MA: MIT Press, 1995.

Gibson, William (1984) Neuromancer New York : Ace Books.

Kahin, Brian. Commercialization of the Internet: Summary Report. Electronic document produced following a workshop by that title held by the Science, Technology and Public Policy program at the John F. Kennedy School of Government, Harvard University, March 1-3, 1990.

King, John Leslie (1991) "What's So Great About Openess? A Dialectical Look At The Open Systems Movement" Proceedings of NORDDATA '91 Oslo: Norway, May 1991. Technical Report, Information and Computer Science, University of California, Irvine CA 92717.

King, J.L., Gurbaxani, V., Kraemer, K.L., McFarlan, F.W., Raman, K.S., and Yap, C.S. Institutional Factors in Information Technology Innovation. Information Systems Research, Vol. 5, No. 2, 1994, pp. 139-169.

King, J.L. and Kraemer, K.L. Information Infrastructure, National Policy, and Global Competitiveness." Information Infrastructure and Policy, Vol 4, No 1, March, 1995, pp. 527.

Krol, Ed. (1993) The Whole Internet: User's Guide and Catalog O'Reilly and Associates Inc.

Leslie, Stuart W. The Cold War and American Science: The military-industrial-academic complex at MIT and Stanford. New York: Columbia University Press, 1993.

March, J.G. and Olsen, J.P. Rediscovering Institutions: The Organizational Basis of Politics. New York: Free Press, 1989.

Meyer, J.W., and Rowan, B. Institutionalized organizations: formal structure as myth and ceremony. American Journal of Sociology, 83:340-363, 1977. 
Moreau, R. The Computer Comes of Age: The People, the Hardware, and the Software. Cambridge: MIT Press, 1984

NAS (National Academy of Sciences). Realizing the Information Future: The Internet and Beyond. Washington, DC: National Academy Press, 1994.

New Multimedia Reviews, January 27, 1995. Adam Curry's Metaverse. On-line entry seen in the Pathfinder web server:

http://www.pathfinder.com/@@cz35xeD38wIAQAgn/ew/

950127/multimedia/259mmshorts.html, updated March 3, 1995.

Newlin, D. Burton, Jr. Standards and Organizations Involved in the Constructing the Information Superhighway. In Kahin, Brian and Janet Abbate (eds.) Standards Policy for Information Infrastructure. Cambridge MA: MIT Press, 1995.

Quarterman, John S. (1990) The Matrix: Computer Networks and Conferencing Systems Worldwide Digital Press.

Quarterman, John. S. (1993) "The Global Matrix of Minds" in Ed. Harasim, Linda Global Networks: Computers and International Communication Cambridge MA: MIT Press.

Quittner, Joshua. Browser Madness. Time Magazine, August 21, 1995. Vol. 146, No. 8.

Pickering, J. and King, J.L. Hardwiring weak ties: Interorganizational ComputerMediated Communication, occupational communities, and organizational change. Organization Science, Vol. 6, No. 4, 1995, pp. 479-486.

RFC 822 (1982) "Standard for the Format of the ARPA Internet Text Messages" Crocker, D. University of Delaware, August 13th

RFC 882 (1983) "Domain Names - Concepts and Facilities" Mockapetris, P. University of Southern California, November.

RFC 1000 (1987) "The Request For Comments Reference Guide" Reynolds, J. and J. Postel, University of Southern California, August. 
RFC 1118 (1989) "The Hitchhikers Guide to the Internet" Krol, E. University of Illinois Urbana-Champaign, September.

RFC 1173 (1990) "Responsibilities of Host and Network Managers: A Summary of the 'Oral Tradition' of the Internet" FTP Software Inc., August.

Roberts, L.G. and Kahn, R.E. "Computer Network Development to Achieve Resource Sharing." AFIPS Spring Joint Computer Conference, 1970: 543-549.

Stephenson, Neal. Snow Crash. New York: Bantam, 1992.

Thompson, R.L. Wiring a Continent: The History of the Telegraph Industry in the United States, 1832-1866. Princeton, NJ: Princeton University Press, 1947

Williams, M.R., A History of Computing Technology. Englewood Cliffs, NJ: Prentice-Hall, 1985 